Chapman University

Chapman University Digital Commons

Psychology Faculty Articles and Research

Psychology

2-22-2016

\title{
What Keeps Passion Alive? Sexual Satisfaction Is Associated With Sexual Communication, Mood Setting, Sexual Variety, Oral Sex, Orgasm, and Sex Frequency in a National U.S. Study
}

David Frederick

Chapman University,dfrederi@chapman.edu

Janet Lever

California State University - Los Angeles

Brian Joseph Gillespie

Sonoma State University

Justin R. Garcia

Indiana University

Follow this and additional works at: http://digitalcommons.chapman.edu/psychology_articles

Part of the Gender and Sexuality Commons, Health Psychology Commons, and the Other Psychology Commons

\section{Recommended Citation}

Frederick, D. A., Lever, J., Gillespie, B. J., \& Garcia, J. R. (2016). What keeps passion alive? Sexual satisfaction is associated with sexual communication, mood setting, sexual variety, oral sex, orgasm, and sex frequency in a national U.S. study. Journal of Sex Research, 54(2), 186-201. doi: 10.1080/00224499.2015.1137854 


\section{What Keeps Passion Alive? Sexual Satisfaction Is Associated With Sexual Communication, Mood Setting, Sexual Variety, Oral Sex, Orgasm, and Sex Frequency in a National U.S. Study}

\section{Comments}

This is an Accepted Manuscript of an article published in Journal of Sex Research, volume 54, issue 2, in 2016, available online at DOI: 10.1080/00224499.2015.1137854. It may differ slightly from the final version.

\section{Copyright}

Taylor \& Francis 


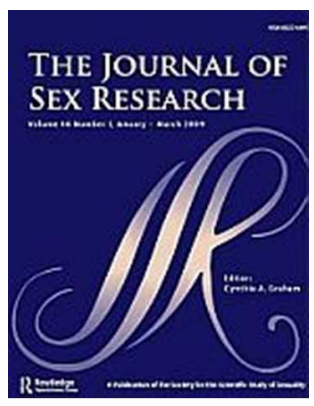

\section{What Keeps Passion Alive? Sexual Satisfaction is Associated with Sexual Communication, Mood Setting, Sexual Variety, Oral Sex, Orgasm, and Sex Frequency in a National U.S. Study}

\begin{tabular}{|r|l|}
\hline Journal: & The Journal of Sex Research \\
\hline Manuscript ID & $15-291$. R2 \\
\hline Manuscript Type: & Original Article \\
\hline Keywords: & $\begin{array}{l}\text { Satisfaction, Psychology and sexuality, Women's sexuality, Normative } \\
\text { Sexual Behavior, Gender Differences }\end{array}$ \\
\hline \multicolumn{2}{|l}{} \\
\hline
\end{tabular}


1

2

3

4

5

6

7

8

9

10

11

12

13

14

15

16

17

18

19

20

21

22

23

24

25

26

27

28

29

30

31

32

33

34

35

36

37

38

39

40

41

42

43

44

45

46

47

48

49

50

51

52

53

54

55

56

57

58

59

60

WHAT KEEPS PASSION ALIVE? 1

\author{
What Keeps Passion Alive? \\ Sexual Satisfaction is Associated with Sexual Communication, Mood Setting, Sexual Variety, Oral \\ Sex, Orgasm, and Sex Frequency in a National U.S. Study
}




\title{
WHAT KEEPS PASSION ALIVE? 2
}

\begin{abstract}
Passion and sexual satisfaction typically diminish in longer-term relationships, but this decline is not inevitable. We identified the attitudes and behaviors that most strongly differentiated sexually satisfied from dissatisfied men and women who had been together for at least three years $(N=$ 38,747). Data were collected in 2006 from cohabiting and married men and women via an online survey on a major national U.S. news website. The vast majority of these participants reported being satisfied with their sex life during their first six months together $(83 \% \mathrm{~W} ; 83 \% \mathrm{M})$. Satisfaction with their current sex life was more variable, with approximately half of participants reporting overall satisfaction $(55 \% \mathrm{~W} ; 43 \% \mathrm{M})$, and the rest feeling neutral $(18 \% \mathrm{~W} ; 16 \% \mathrm{M})$ or dissatisfied $(27 \% \mathrm{~W} ; 41 \% \mathrm{M})$. More than one in three respondents $(38 \% \mathrm{~W} ; 32 \% \mathrm{M})$ claimed their sex life was as passionate now as in the beginning. Sexual satisfaction and maintenance of passion were higher among people who had sex most frequently, received more oral sex, had more consistent orgasms, and incorporated more variety of sexual acts, mood setting, and sexual communication. We discuss implications of these findings for research and for helping people revitalize their sex lives.
\end{abstract}




\section{WHAT KEEPS PASSION ALIVE? 3}

Keeping sexual activity fresh and lively as relationships progress is important to many men and women, but couples can find it challenging to maintain sexual satisfaction over a long period of time (Christopher \& Sprecher, 2000). Maintaining passion over time is considered an even more elusive goal, and it is believed that only a small subset of people sustain passion in long-term relationships (Hatfield, Pillemer, O’Brien, \& Le, 2008; O’Leary et al., 2012). To keep their sex lives from fizzling, couples employ a variety of strategies, including communicating their desires to their partners, trying new sexual positions and activities, and consulting sexual self-help magazines, books, and videos. Yet, little is known about the efficacy of such strategies in promoting greater feelings of passion and sexual satisfaction in their relationship.

The importance of sexual satisfaction in relationships makes it critical to understand the attitudes and behaviors that enhance people's sexual lives. Drawing on a large U.S. dataset, the primary goal of the current study was to examine behaviors and attitudes of heterosexual men and women who are sexually satisfied versus those who are sexually dissatisfied. We draw attention to common romantic and sexual behaviors that are rarely assessed in the literature but are likely important contributors to sexual satisfaction and maintaining sexual passion. These include intimate behaviors (e.g., cuddling, kissing, laughing together during sexual activity), incorporating sexual variety (e.g., trying new sexual positions; wearing lingerie), and setting a romantic/sexual mood (e.g., lighting candles; playing music). We also examined commonly assessed behaviors that have been the focal point of previous research (e.g., frequency of sex, oral sex, and orgasm).

\section{Potential Contributors to Sexual Satisfaction: Less Commonly Studied Behaviors}

There are many sexual and affectionate behaviors couples incorporate into their sex lives, but the prevalence and importance of these behaviors for enhancing sexual satisfaction is rarely documented. For instance, in cultures where kissing is part of the romantic-sexual repertoire, it is 


\section{WHAT KEEPS PASSION ALIVE? 4}

an important part of arousal and sustaining feelings of closeness before, during, and after sex acts (Jankowiak, Volshe, \& Garcia, 2015). However, few studies have examined this intimate act, despite the pioneering work of Alfred Kinsey and associates who showed considerable social class differences in frequency of kissing, even distinguishing between lip and "deep" or tongue kissing (Kinsey, Pomeroy, \& Martin, 1948; Kinsey, Pomeroy, Martin, \& Gebhard, 1953). Both men and women report higher sexual satisfaction when they report more frequent kissing, cuddling, touching, and caressing with their partner (Heiman et al., 2011). Yet, few studies have explicitly studied "after play" even though it is known that most men and women desire affectionate behavior, such as "pillow talk" (Denes, 2012) or kissing and cuddling with a partner after sexual activity (Hughes \& Kruger, 2011; Muise, Giang, \& Impett, 2014; van Anders, Edelstein, Wade, \& SamplesSteele, 2013).

Extent of foreplay and length of sexual encounters also matter for sexual satisfaction (Muise et al., 2014), although few studies track these variables. Perhaps most important, for women, having more foreplay increases the likelihood of orgasm (Singh, Meyer, Zambarano, \& Hurlbert, 1998), but interpretation is difficult because most researchers do little to delineate what goes on during the catch-all phrase "foreplay." Recent studies based on representative national samples showed that genital stimulation and oral sex during last sexual encounter were associated with greater sexual satisfaction and pleasure (de Visser, Smith, Rissel, Richters, \& Grulich, 2003; Herbenick et al, 2010c).

Extending the duration of sexual activity by engaging in different intercourse positions is likely a common practice, as was suggested by Alex Comfort (1972) in his groundbreaking sex manual Joy of Sex. Yet relatively little research has been done to support or negate this claim. Nonetheless, human sexuality textbooks often recommend variety in sexual repertoire as a way to 


\section{WHAT KEEPS PASSION ALIVE? 5}

enhance sexual satisfaction, including trying different sex positions and other activities. One of the best-selling textbooks, in its twelfth edition, includes two pages under the subheading "Sexual Variety: An Important Ingredient," but provides no citations to supporting studies (Crooks \& Baur, 2014). Early research on specific sexual acts found that women desired more activities that demonstrate love and intimacy (e.g., talking more lovingly, being more complimentary), whereas men focused on sexual activity itself, desiring more partner initiative, rough play, and talking dirty (Hatfield, Sprecher, Pillemer, Greenberger, \& Wexler, 1988).

While sexual variety is deemed important for sexual satisfaction, evidence on the effectiveness of specific forms of variety, such as use of sex toys or watching pornography together, is lacking. In a representative sample of heterosexual women aged 18-60 in the U.S., 40\% had used a vibrator with a partner during sex play/foreplay (Herbenick et al, 2010a). Interview studies examined how women feel about sex toys (Fahs \& Swank, 2013), but elaboration of the range of sex toys and sex aids available to enhance a couple's experience is left to writers of sex self-help books (e.g., Castleman, 2008). Some newer studies included data on using pornography together as a sex stimulant for couples (Poulsen, Busby, \& Galovan, 2013). Similarly, the prevalence of anal intercourse has been widely studied, but the relationship between anal sex and sexual satisfaction is largely unexamined, and relatively little scholarly attention has been given to anal sexual behaviors other than anal intercourse (see Agnew, 2000; McBride \& Fortenberry, 2010). Sex therapists, on the other hand, have contributed practical knowledge. For example, based on volunteers who expressed interest in experiencing more pleasure from anal stimulation, Morin (2010) contributed a popular self-help guide to disseminate information on anal eroticism.

Missing most of all from the scientific literature are data on whether couples find ways to set aside time for sexual activity, and whether taking time to set a romantic mood affects sexual 


\section{WHAT KEEPS PASSION ALIVE? 6}

satisfaction. Going on a romantic getaway is one way to change the scene for different, or perhaps more leisurely, lovemaking, at least according to common sexual self-help advice. But how many couples do this? An alternative is a "date night" where couples are reminded to set the scene and spend time focusing on each other and their romantic/sexual life as a couple. But little is known about whether setting a mood, such as dimming the lights or turning on favorite music, matter for sustaining satisfaction and passion. To really understand how couples can sustain passion over time, we need to know more about what behaviors couples engage in, and if these behaviors are actually associated with sexual satisfaction.

\section{Potential Contributors to Sexual Satisfaction: More Commonly Studied Behaviors}

Frequency of vaginal intercourse, oral sex, and orgasm have been established as contributors to sexual satisfaction. Couples who have sex more often report greater satisfaction with their sex life (Laumann, Gagnon, Michael, \& Michaels, 1994), but the "honeymoon effect" of declining sex frequency can begin after a relatively short time together (Call, Sprecher, \& Schwartz, 1995). Drawing a distinction between passionate and companionate love, intimate relationship experts attribute part of the decline to the dimming of passion after the exciting early days of falling in love (Hatfield \& Rapson, 1993); their assumptions are often rooted in Sternberg's (1986) triangular theory of love, in which he asserted that passion develops rapidly and intensely in the early stages of love relationships and then subsides almost as quickly, leaving couples who do not experience growth in both intimacy and commitment with vulnerable relationships.

Christopher and Sprecher (2000) concluded that sexual satisfaction and frequency of sex both decline, but for reasons not well understood, sexual satisfaction does not decline as dramatically as does frequency of sex. One possible intervening variable between intercourse frequency and sexual satisfaction is consistency of orgasm. People who orgasm more frequently 


\section{WHAT KEEPS PASSION ALIVE? 7}

report more sexual satisfaction (Haavio-Mannila \& Kontula, 1997; Sprecher \& Cate, 2004).

Despite changes in sexual frequency, certain specific sexual behaviors likely affect both sexual satisfaction and orgasm frequency. Oral sex (both fellatio and cunnilingus) is practiced by the majority of U.S. men and women in relationships (Herbenick et al., 2010b; Kaestle \& Halpern, 2007). In the current study we assessed people's reports about their sex life currently versus in the beginning of their relationship to provide a new way to assess this honeymoon effect, and examined how frequency of sexual intercourse, oral sex, and orgasm were related to sexual satisfaction.

Aside from sexual acts, sexual satisfaction is known to be associated with relationship satisfaction (Christopher \& Sprecher, 2000; Sprecher, 2002). Recent research suggests that the relationship between sexual satisfaction and relationship satisfaction is reciprocal (Byers, 2005). Couples who enjoy pleasurable sex reap the reward of having more relationship satisfaction, but those who work on the intimacy of their relationship may find those traits carrying over to enhance their sex life.

One way to promote sexual satisfaction is constructive communication (MacNeil \& Byers, 2005). People who employ sexual communication techniques (being open about sexual desires and fantasies; communicating about sexual likes and dislikes) are generally more satisfied with their sex lives (Montesi, Fauber, Gordon, \& Heimberg, 2010). Although past research has examined sexual communication, we could not find a published and validated sexual communication scale that included an item regarding someone saying "I love you" during sex, which is consistent with the lack of research focus on intimate behaviors during sexual activity noted earlier. The current study assessed how six different examples of sexual communication were linked to sexual satisfaction.

\section{Demographic and Control Variables}




\section{WHAT KEEPS PASSION ALIVE? 8}

The literature has produced conflicting findings on gender differences in sexual satisfaction. The most recent meta-analysis of 29 studies showed that men were more satisfied than women, but only slightly so $(d=.17$; Petersen \& Hyde, 2010). Ethnicity, age (controlling for relationship length), and socioeconomic status are generally unrelated to sex frequency and satisfaction (for reviews, see Christopher \& Sprecher, 2000; Sanchez-Fuentes, Santos-Iglesias, \& Sierra, 2014; Rehman, Fallis, \& Byers, 2013). Additionally, having children in the home can also negatively impact sexual satisfaction and frequency (Gray, Garcia, Crosier, \& Fisher, 2015).

\section{Current Study}

Based on the existing literature, we proposed the following hypotheses. People will report more sexual satisfaction and behaviors enhancing their sex life in the early phase of their relationship than now (H1). Compared to sexually dissatisfied people, sexually satisfied people will: report more consistent orgasms and more frequent oral sex $(\mathrm{H} 2)$, incorporate more acts of sexual variety in their sex lives (H3), incorporate more communication strategies (H4), and incorporate more mood setting techniques (H5). Sexually satisfied people will report more sexual acts, more positive emotions, and longer duration of sex during their last sexual encounter (H6), engage in the same or greater degree of positive practices during sex as they did in the beginning of their relationship (H7), make more successful use of self-help advice in magazines and books (H8), and report more positive sexual attitudes towards their sex lives (H9). Finally, we conducted exploratory analyses to determine what differentiates people high in sexual satisfaction whose passion has not waned from people high in sexual satisfaction but who have experienced diminished passion.

\section{Method}




\section{WHAT KEEPS PASSION ALIVE? 9}

\section{Participants}

The present study is based on secondary analyses of anonymous data collected via a survey posted on the official website of NBC News for ten days in 2006. ELLE magazine and NBCNews.com contributed to survey construction and jointly sponsored this project, as well as others on popular topics during the decade. Secondary data analysis of anonymized public or private datasets are IRB exempt at both Chapman University and according to U.S. federal guidelines (exemption category 4; National Institutes of Health, 2010).

In the overall sample, there were 72,008 heterosexual men and women (51\% men, 49\% women) ages $18-65$. We focused our analyses on 38,747 people (59\% men, $41 \%$ women) who fit the following criteria: completed the full survey via the NBCNews.com entry portal; indicated they were married, remarried, or living with their partner; and reported being with their partner for 3 or more years. The current paper and analyses focus on heterosexual participants (we examine sexual orientation differences in correlates of sexual satisfaction in a separate manuscript). The average age in the sample was 39.9 years $(S D=10.0)$, with men $(42.4, S D=9.7)$ approximately 6 years older than the women $(36.3, S D=9.3), t(38745)=62.83, p<.001$.

Men are overrepresented in the analyzed subsample of participants because a key inclusion criteria for our analyses was married and cohabiting people who had been in a relationship for 3 years or longer. There are more unmarried women than men in the population ( 88 unmarried men for every 100 married women) and men in the sample were older than women and therefore more likely to be married. Table 1 presents key demographics for the analyzed sample and for men and women separately.

Participants were invited to take the "ELLE/msnbc.com Sex and Love" survey and clicked on banner ads that appeared on the NBCNews.com website homepage and Health section of the 
WHAT KEEPS PASSION ALIVE? 10

website (the vast majority of the respondents came from the homepage, drawing in a broad and diverse audience). All respondents were provided with an opportunity to view the privacy agreement and asked for their birth year; those under age 18 were dismissed as too young to participate. The wording (or shorthand approximations of the wordings) for each of the individual items are shown in the tables (an Appendix that includes the survey items reported in this manuscript is available online as a supplementary file).

Market research on NBCNews.com (formerly msnbc.com) shows that at the time of the survey it routinely ranked among one of the most popular websites in the United States. Its 58 million unique monthly visitors include a broad diversity of people in terms of age, income, and political orientation (NBCNews.com Media Kit, 2012; note that msnbc.com, the general news website, was a different entity than MSNBC TV and had substantially different demographics, including approximately equal numbers of Democrat and Republican visitors). The authors were granted access to the several anonymous data sets for secondary data analysis, including the study reported here. Zip code data in one dataset showed that more than $95 \%$ of respondents came from the United States and, in a second dataset, over 98\% reported living in the United States. The fact that the sample is almost exclusively U.S. residents is consistent with NBCNews.com's own market analyses of their website visitors (NBCNews.com Media Kit, 2012).

Datasets on various topics garnered through this site between 2002 and 2010 have been used to conduct research on mate preferences (Fales et al., 2016), sexual jealousy (Frederick \& Fales, in press), sexual regrets (Galperin et al., 2013), sexual experience (Frederick \& Jenkins, 2015), consequences of visiting online sex sites (Grov et al., 2011), gender differences in beliefs about who should pay for dates (Lever, Frederick, \& Hertz, 2015), attitudes towards female bosses (Elsesser \& Lever, 2011), friendship (Gillespie, Frederick, Harari, \& Grov, 2015; Gillespie, Lever, 
WHAT KEEPS PASSION ALIVE? 11

Frederick, \& Royce, 2014), and aspects of body image (Frederick, Lever, \& Peplau, 2007; Frederick, Peplau, \& Lever, 2006, 2008; Frederick, Sandhu, Morse, \& Swami, in press; Lever, Frederick, Laird, \& Sadeghi-Azar, 2007; Lever, Frederick, \& Peplau, 2006; Peplau et al., 2009). Measures

\section{Sexual satisfaction and passion outcome variables}

Sexual satisfaction and sexual satisfaction groups. We assessed beliefs about sexual satisfaction in the beginning of the relationship versus now. First we asked, "How satisfied were you with your sex life during your first six months together?" The next item, our central outcome variable, asked "How satisfied are you with your sex life now?" Participants provided their answers on a 7-point Likert scale $(1=$ Very Dissatisfied, $4=$ Neutral, $7=$ Very Satisfied $)$. These questions allowed us to test the extent to which people believe their sexual satisfaction is relatively lower or higher than in the past. We used their current ratings as a continuous variable in regression and ANOVA analyses (e.g., Table 2 and Figure 1). To validate this item, we conducted a separate study of 550 adults in a survey posted in the volunteers section of the Craigslist.org website and found that responses on this measure correlated highly $(r=.91)$ with the Global Measure of Sexual Satisfaction Scale (Lawrance \& Byers, 1995).

A major goal was to create a readily accessible profile of attitudes and behaviors of sexually satisfied versus dissatisfied men and women. Based on their scores on the variable assessing sexual satisfaction now, we classified participants as being sexually Dissatisfied $(1-3 ; n=13,666)$, Neutral $(4 ; n=6,476)$, or Satisfied $(5-7 ; n=18,605)$. These groupings enabled us to compare the practices and attitudes of people with differing levels of sexual satisfaction. 
WHAT KEEPS PASSION ALIVE? 12

Beliefs about passion. We assessed whether people believed passion had changed over time: "We have as much passion in our sex life as when we first started having sex" $(1$ = Strongly Disagree, 2 = Somewhat Disagree, 3 = Somewhat Agree, 4 = Strongly Agree).

Beliefs about changes in sex life over time. To explore beliefs about changes in sex life over the duration of the relationship, we provided participants a list of feelings and behaviors and asked "Comparing your sex life early in your relationship to your sex life now, which of the following happened more often then, which happens more often now, and what has stayed about the same?" Participants responded with "more then," "same," "more now," or "Not Applicable / Does not apply to us." Abbreviated versions of the items are shown in Figure 2.

\section{Demographic variables}

Demographic variables included gender, age, relationship length, education level, and number of children. Participants indicated if their relationship length was 3-5 years, 6-10 years, 1120 years, $>20$ years; these were recoded as $4,8,16$, and 30 years, respectively. In order to retain the relative ordering of the education levels when using education as a predictor variable in regression analyses (Pasta, 2009), education was coded from lower ( 1 = some high school education or less $)$ to higher $(5=$ graduate degree $)$. For parental status, participants indicated the number of children in their home under age 21 years, ranging from 0 to $6+($ see Table 1$)$.

\section{Frequency and consistency variables}

Sex frequency. Participants were asked "How often do you typically have sex with your partner?" and the responses were recoded to reflect the approximate number of times each participant reported having sex each month $(0=$ Not at all, $.50=$ Once every few months, $1=$ Once a month, 2 = Two or three times a month, $6=$ Once or twice a week, $14=$ Three to four times a week, 20 = Five or more times a week, and $32=$ More than once a day). 
Oral sex frequency. Participants were asked two questions: "During your lovemaking in the past month, how often did you [give oral sex to your partner] / [receive oral sex from your partner]" ( 1 = Never, $2=$ Rarely, $3=$ About half of the time, $4=$ Usually, $5=$ Always $)$.

Participants indicating "not applicable, we were not intimate" were excluded from analyses involving these variables. The full continuous variable was used in regression, and the scale was collapsed to make three categories (Never-Rarely, About half of the time, Usually-Always) when presenting some results to facilitate data presentation (e.g., Table 3).

Orgasm consistency. Participants were asked two questions: "During the past month, how often did [you] / [your partner] reach orgasm when you and he or she were intimate?" $(1=$ Never, 2 $=$ Rarely, $3=$ About half of the time, $4=$ Usually, $5=$ Always $)$.

\section{Sexual variety and communication variables}

Acts of sexual variety. Participants were given a list of 17 different activities and were asked "Have you done any of the following in the past year to improve your sex life? If so, select all that apply". The full list of activities is shown in Table 4. We coded affirmative responses as 1 for each activity, and created an acts of sexual variety variable by summing the responses (range 017; $0=$ none of these activities, $17=$ all of these activities).

Sexual communication. Participants were given a list of six different types of sexual communication and asked "In the past month, have you and your partner talked about sex in any of these ways? Please select all that apply." The full list of communication strategies are shown in Table 4. We coded affirmative responses as 1 , and created a communication variable by summing the responses for the 6 items (range 0-6). 
WHAT KEEPS PASSION ALIVE? 14

We also examined event-level data, which may be less prone to recall biases. Participants were asked about their activities during the last time they had sex. If these behaviors are representative of what couples typically do, they may provide information about which practices are linked to greater sexual satisfaction. Consistent with the idea that event-level data is informative about general practices, $87 \%$ of women and $92 \%$ of men who received oral sex during their last sexual encounter reported usually-always receiving oral sex in the past month. In contrast, reports of oral sex during last encounter were lower if participants reported oral sex half of the time (49\% $\mathrm{W} ; 59 \% \mathrm{M})$ and lowest if they reported oral sex never-rarely $(9 \% \mathrm{~W} ; 11 \% \mathrm{M})$ during the past month. The full list of items can be seen in Table 5 .

Mood setting DLS. Five of the items described things people might have done to set the mood (e.g., playing music in the background or lighting a candle). Participants could check all items that applied. We coded affirmative responses as 1 , and created a mood setting variable by summing the responses for the 5 items (range 0-5).

Sex acts DLS. Eight items described actions that people might have engaged in during their last sexual encounter (e.g., gentle kissing). Participants could check all items that applied.

Feelings DLS. Participants indicated the one option that best described how they felt during their last sexual encounter (e.g., passionate; playful; pressured).

Duration of Sex DLS. Participants were asked "how much time was spent on that occasion, from the time physical contact began until it ended (including kissing, petting, etc.)?”

\section{Reading sexual self-help magazines variable}

We assessed men and women's use of magazines for sex tips. Participants were asked "Do you ever read magazine articles or books that promise to put the spark back in your sex life?" (see response options in Table 6). 
WHAT KEEPS PASSION ALIVE? 15

\section{Attitudes about sex life and relationship variables}

A series of items assessed people's overall relationship satisfaction and attitudes about their sex life (e.g., I feel comfortable asking my partner for what I want in bed). The full list of items is presented in Table 6. Participants responded on a four point Likert scale $(1=$ Strongly Disagree, 2 = Somewhat Disagree, 3 = Somewhat Agree, $4=$ Strongly Agree). To facilitate data presentation, we also identified the percentage of participants who disagreed (1-2) versus agreed (3-4) with the statements. Participants could indicate not applicable on these items $(N \mathrm{~s}=115-724$ across the items) and these participants were excluded from analyses using these items.

\section{Results}

\section{Data Analysis Overview}

Due to the large sample size, even minuscule effects emerged as statistically significant (e.g., $\beta \mathrm{s}$ as small as .02 and percentage differences as small as 1 percentage point), making effect size particularly important to emphasize. For regression analyses, we present the standardized regression coefficients $(\beta)$ and elected to highlight statistically significant results in the text when they reflected $\beta$ values greater than |.09|. We do not present results separately by ethnicity because a series of ANOVAs examining the effects of ethnicity on all of the continuous variables showed that, even when the effects were statistically significant, they were minuscule in size (all $\eta \rho^{2}<.005$, except for education and age, $\left.\eta \rho^{2}=.01\right)$.

We conducted regression analyses examining the predictors of sexual satisfaction and feeling passion during sex (Table 2). Model 1 includes all of the relevant predictors, including relationship satisfaction and sex frequency. Model 2 removes relationship satisfaction and sex frequency as predictors because sexual satisfaction is likely a component of relationship satisfaction and sex frequency is likely tightly intertwined with sexual satisfaction (people who are satisfied 
WHAT KEEPS PASSION ALIVE? 16

may choose to have more sex). The pattern of results was generally similar in Model 1 and Model 2, except the effects of the other predictors were generally stronger when relationship satisfaction and sex frequency were removed. We show the results for both models in Table 2, but focus on the patterns found in Model 2 in the results. Skewness was low in all continuous variables $(<|1.6|$ for all variables, and $<|1.0|$ for majority of variables $)$, as was kurtosis $(<|2.0|$ for all variables, except for sex frequency $=2.4$ ). Collinearity diagnostics revealed that multicollinearity was low for all predictors (all Tolerance values .50-1.0, all VIF values 1.0-2.0).

We also divided the participants into groups of "Satisfied," "Neutral," and "Dissatisfied" men and women to create profiles of the attitudes and behaviors of these different groups. We conducted Chi-square analyses comparing percentage of Satisfied versus Dissatisfied men and women engaging in each behavior (see Tables 3-6).

\section{Hypothesis 1. People Will Report More Satisfaction and Behaviors Enhancing Their Sex Life in the Early Phase of Their Relationship Than Now}

Approximately equal percentages of men were Satisfied now (43\%) as opposed to Dissatisfied now (41\%), with the remainder being Neutral now (16\%). In contrast, a majority of women were Satisfied now (55\%), with fewer women Dissatisfied now (27\%) or Neutral now (18\%). From the lowest point (1) to the highest point (7) on the Likert scale, the percentage of men and women at each level of sexual satisfaction now were: $1=$ Very Dissatisfied $(15 \% ; 10 \%), 2$ $(12 \% ; 7 \%), 3(14 \% ; 10 \%), 4=$ Neutral $(16 \% ; 18 \%), 5(18 \% ; 18 \%), 6(15 \% ; 19 \%), 7=$ Very Satisfied $(10 \% ; 17 \%)$. This is in sharp contrast to reports of how sexually satisfied these participants were early in the relationship, where $83 \%$ of men and $83 \%$ of women reported being Satisfied, $8 \%$ of men and $7 \%$ of women Neutral, and only $9 \%$ of men and $10 \%$ of women Dissatisfied. 
ANOVA analyses. Participants rated their sexual satisfaction now and their recollection of their sexual satisfaction during the first six months together. Using a 2 (Now vs. First 6 Months) X 2 (Gender) X 2 (Relationship Length) Mixed ANOVA, we examined whether people reported that their sexual satisfaction was higher now or in the first six months of their relationship. The results are shown in Figure 1. Consistent with the hypothesis, there was a main effect of Now versus First 6 Months, with people reporting substantially greater satisfaction in the first 6 months, $F(1,38739)$ $=14323, p<.001, \eta \rho^{2}=.27, d=.68$. All other main effects and interactions were significant $(p \mathrm{~s}<$ $.005)$, but only the main effect of gender exceeded $\eta \rho^{2}=.01\left(\eta \rho^{2}=.011\right)$.

Frequency Distributions. We asked participants to report if certain practices and feelings were more common now versus when they first started having sex, or if things were about the same. People's reports were quite varied (Figure 2). Analyses for gender differences are reported in Table 6 (last column). Here we highlight a few key findings.

Many people reported that sex, foreplay, and oral sex were more frequent early in the first six months. One-third of women, however, stated they orgasmed more frequently now, and onefourth reported having multiple orgasms more frequently now. Also notable is that more women felt less sexually inhibited now (38\%) than in the early months of their relationship (24\%).

Feeling desire from partners appears to be more of a problem for men than for women. Three-fifths of men reported feeling more desired by their partner early in their relationship compared to two-fifths of women. Close to two-thirds of men, however, reported more desire or the same level of desire for their partner now as in the past compared to only half of women. Notably, more women (36\%) reported feeling emotional closeness during sex now than in the first six months of their relationship (27\%), whereas slightly more men $(31 \%)$ felt closer in those early days compared to now (27\%). Very few men and women said there was more hugging and 
WHAT KEEPS PASSION ALIVE? 18

cuddling now in their relationship, with most men and women saying there is the same amount $(43 \% ; 43 \%)$ or that there was more early on $(38 \% ; 38 \%)$.

\section{Hypothesis 2. Satisfied People Will Report More Consistent Orgasms and More Frequent Oral Sex than Dissatisfied People}

Consistent with the hypotheses, men were more sexually satisfied and reported more passion when they reported more consistent orgasms $(\beta=.11 ; \beta=.07)$, when their partners had more consistent orgasms $(\beta=.11 ; \beta=.12)$, and when they received oral sex more often $(\beta=.11 ; \beta$ $=.07$; Table 2). Consistent with the hypotheses, women who reported more consistent orgasms were more likely to be satisfied with their sex lives and reported more passion in their sex life $(\beta=$ $.27 ; \beta=.22$ ). With the controls in the model, however, oral sex frequency and partner's consistency of orgasm did not emerge as strong predictors.

These patterns were seen in the consistency of orgasm and oral sex among dissatisfied and satisfied men and women (Table 3). Among men, satisfied men were more likely than dissatisfied men to say that they usually-always orgasmed (98\% vs. $91 \%)$, and that their partner did as well (79\% vs. 61\%). Satisfied men were more likely than dissatisfied men to usually-always receive oral sex (31\% vs. 15\%) and to give oral sex (56\% vs. 37\%). Among women, satisfied women were more likely than dissatisfied women to say that they usually-always orgasmed (78\% vs. 41\%), and that their partner did as well (98\% vs. $80 \%)$. Satisfied women were more likely than dissatisfied women to usually-always receive oral sex (30\% vs. 18\%) and to give oral sex (30\% vs. $24 \%)$.

Hypothesis 3. Satisfied People Incorporate More Acts of Sexual Variety in their Sex Life than Dissatisfied People

Consistent with the hypothesis, men and women who reported more acts of sexual variety reported more sexual satisfaction $(\beta=.18 \mathrm{men} ; \beta=.10$ women $)$ and passion $(\beta=.14 ; \beta=.10$ 
women; Table 2). Figure 3 shows the mean levels of sexual satisfaction for men and women according to number of acts of sexual variety performed.

Sexually satisfied men and women were more likely to engage in almost all of the acts of sexual variety than dissatisfied men and women (Table 4, top). In terms of the biggest percentage point differences, satisfied men and women were more likely than dissatisfied men and women to say that they: tried a new sexual position, wore sexy lingerie, took a shower/bath, talked about or acted out fantasies, gave or had a massage, went on a romantic getaway, tried anal stimulation, made a date night to have sex, or used a sex toy together.

\section{Hypothesis 4. Satisfied People Will Incorporate More Communication Strategies than} Dissatisfied People

Regression analyses. Consistent with the hypothesis, men and women who reported using more communication strategies were more sexually satisfied $(\beta=.18$ men; $\beta=.18$ women $)$ and reported more passion $(\beta=.14$ men; $\beta=.16$ women; Table 2$)$ than men and women who reported fewer communication strategies. Figure 4 shows the mean levels of sexual satisfaction for men and women according to number of communication strategies they employed.

Sexually satisfied men and women were more likely to use five of the six communication strategies than dissatisfied men and women (Table 4, bottom), and the differences were marked. In terms of these five types of communication, between $33-56 \%$ of satisfied men and women used each type compared to only $11-30 \%$ of dissatisfied men and women. The only exception was that very few participants gently criticized how their partner did something in bed.

\section{Hypothesis 5. Satisfied People Will Incorporate More Mood Setting Techniques DLS than} Dissatisfied People 
WHAT KEEPS PASSION ALIVE? 20

Consistent with the hypothesis, during their last sexual encounter, men and women who used more mood setting techniques were more sexually satisfied $(\beta=.20$ men; $\beta=.20$ women) and reported more passion ( $\beta=.20$ men; $\beta=.22$ women; Table 2$)$ than men and women who used fewer mood setting techniques. Satisfied men and women were more likely to use all of the mood setting techniques than were dissatisfied men and women (Table 5, top).

\section{Hypothesis 6. Satisfied People Will Report More Sexual Acts, More Positive Emotions, and Longer Duration of Sex During Their Last Sexual Encounter than Dissatisfied People}

Consistent with the hypothesis, sexually satisfied men and women were more likely than sexually dissatisfied men and women to engage in all of the sexual acts listed, including gentle kissing $(+17 \% ;+27 \%)$, deep kissing $(+23 \% ;+31 \%)$, and changing positions during sexual intercourse $(+28 \% ;+27 \%$; Table 5 , middle).

Satisfied men and women were more likely than dissatisfied men and women, respectively, to say their last encounter was passionate, loving and tender, or playful (Table 5, middle). Overall, women were more likely than men to say they were just going through the motions for their partner's sake ( $21 \%$ vs. $7 \%$ ), and dissatisfied women were much more likely than satisfied women to say they were just going through the motions (43\% vs. $7 \%$ ). Men were more likely than women to say they were just happy to be getting a release from tension (32\% vs. $14 \%)$. Dissatisfied men were much more likely than satisfied men to see their last sexual encounter as a release from tension (47\% vs. $15 \%)$.

Sexually satisfied men and women also reported that their last sexual encounter lasted longer than did dissatisfied men and women (Table 5, bottom). Satisfied men and women were more likely than dissatisfied men and women to say their sexual encounter lasted more than 30 minutes, and were less likely to say it lasted fifteen minutes or less. 
WHAT KEEPS PASSION ALIVE? 21

\section{Hypothesis 7. Satisfied People Will Report Engaging in the Same or a Greater Degree of Positive Practices During Sex as They Did in the Beginning of Their Relationship than Dissatisfied People}

Consistent with the hypothesis, sexually satisfied men and women were more likely than dissatisfied men and women to report the same or a greater level of positive sexual practices now as during the beginning of their relationship (Table 6, top). Sexually satisfied men and women were more likely than dissatisfied men and women, respectively, to report feeling desire for their partner and feeling desired by their partner. They also engaged in more foreplay, sex, receiving oral sex, giving oral sex, reaching of orgasm during sex, and having more than one orgasm during sex. This pattern extended to intimacy during sex: sexually satisfied participants had higher levels of emotional closeness and hugging/cuddling after sex.

\section{Hypothesis 8. Satisfied People Will Make More Successful Use of Magazines and Books than}

\section{Dissatisfied People}

Consistent with the hypothesis, sexually satisfied men and women were more likely than dissatisfied men and women to make successful use of sex advice found in magazines and books (Table 6, middle). They were not more likely to read advice with suggestions for ways to keep sex fresh or lively, but they were more likely to say they read sources for this type of advice, tried some of the suggestions, and found them effective. They were less likely to say they simply read such advice but did not test out the ideas proposed.

\section{Hypothesis 9. Satisfied People Will Report More Positive Sexual Attitudes than Dissatisfied}

\section{People}

Consistent with the hypothesis, sexually satisfied men and women were more likely than dissatisfied men and women to have positive attitudes about their sex life and their relationships 
WHAT KEEPS PASSION ALIVE? 22

with their partner (Table 6, bottom). They were more likely to report feeling happy with their relationship, comfortable asking their partner for what they want in bed, satisfied with the number of sexual positions they use with their partner, and that their sex life was as passionate and spontaneous now as it was in the beginning. They were less likely to report that their sex life was predictable, that they found their partner more physically attractive in the beginning, that they did not feel good enough in bed with their partner, and that their partner did not know how to excite them.

For men, there was little variation in the importance they placed on having an exciting sex life. Nearly all men felt that having an exciting sex life was important, regardless of their current sexual satisfaction, although men who were neutral in satisfaction scored a bit lower in the importance placed on an exciting sex life than other men. For women, however, there was more variation. Satisfied women were most likely to place importance on an exciting sex life. Interestingly, women neutral in satisfaction were less likely to place importance on an exciting sex life than satisfied and dissatisfied women. For dissatisfied women, one reason for their dissatisfaction may be that they were not experiencing something important to them, whereas neutral women may place less importance on sex, whether exciting or not.

\section{Profile of the Subsample of Satisfied People Who Reported Enduring Passion}

Finally, we examined what differentiated sexually satisfied men and women who reported no decline in passion from sexually satisfied men and women who reported lower passion now. The high passion-high sexual satisfaction men $(n=6,159)$ and women $(n=5,272)$ were more likely than lower passion-high sexual satisfaction men $(n=3,833)$ and women $(n=3,324)$ to have more frequent sex (men's $d=.54$; women's $d=.59)$, more consistent orgasm $(d=.08 ; d=.34)$, received more oral sex $(d=.29 ; d=.36)$, engaged in more mood setting $(d=.41 ; d=.44)$, engaged 
in more communication $(d=.40 ; d=.36)$, engaged in more acts of sexual variety $(d=.34 ; d=.46)$, and were more satisfied with their relationships $(d=.50 ; d=.50, p<.001)$. All differences were significant at the $p<.001$ level (except differences in male orgasm frequency, which was not significant). The groups had similar relationship lengths $(d=.10, p=.02 ; d=.02, p=.34)$.

\section{Discussion}

Using a large U.S. sample of men and women in relationships for three or more years, we examined a wide variety of factors and to see whether they contribute to maintaining sexual satisfaction. It is clear most people felt that their sexual satisfaction and passion declined over time. The drop in sexual passion is consistent with studies finding a decline in feelings of passionate love over time (Hatfield et al., 2008). But perhaps more interesting is the fact that our data call into question the application of Sternberg's (1986) thesis that passion quickly subsides. Our data show that, if properly nurtured, passion can last for decades. Nearly two-thirds of sexually satisfied respondents reported that their sex lives were as passionate as in early days together; beyond that global statement, over one-third of sexually satisfied men and women selected "passionate" as the single best word (out of six) to describe their most recent sexual encounter.

We believe our data also help answer a few questions important in current sexology. In their literature review, Christopher and Sprecher (2000) concluded that the field does not really understand why, as relationships mature, sexual satisfaction does not diminish as steeply as frequency of sexual activity. Our data suggest that items that measure the emotional component of sexual encounters deserve more study to help understand whether improved quality may balance reduced quantity of sex. One in three women, but also more than one in four men, said they feel more emotional closeness during sex now than at the start of their relationship. To name just a few items, hugging, cuddling, afterplay, and saying "I love you," can be part of sex and as deserving of 


\section{WHAT KEEPS PASSION ALIVE? 24}

study as climaxing. This is consistent with findings showing that both men and women rate sexual activity in more committed relationship contexts as more sexually and emotionally satisfying than in more uncommitted contexts (Mark, Garcia, \& Fisher, 2015).

Further limiting our understanding is the narrow number of sex behaviors that are measured in most studies. Readers of the National Health and Social Life Survey (NHSLS; Laumann et al., 1994) might ask why people were so content with their sex lives in light of the finding that $87 \%$ of the married Americans in that representative sample claimed to be "extremely" or "very physically pleased" by their sexual relationship, while at the same time their answers to behavioral items drew a portrait of somewhat routinized sex. With the addition of questions on mood setting and on a wider variety of sex and intimate behaviors, our data lead us to question how routine people's sex lives really are. Take a single example: anal intercourse is widely studied because it entails health risks, whereas prevalence of anal stimulation is virtually unknown. When asked just about the past year, twice as many of our respondents had engaged in anal stimulation as anal intercourse (30\% vs. 14\%). Some couples' active efforts to keep sex lively focus on quality and variety over quantity, but we cannot know the extent to which this is true unless we ask a broader spectrum of questions, including many behavioral items unrelated to health outcomes and risks such as pregnancy and disease.

Our survey found a smaller proportion of respondents reporting high levels of sexual satisfaction than the NHSLS, perhaps because our respondents were first forced to contrast sex now with sex earlier. In the NHSLS, a significantly larger portion of men more satisfied than women, while the largest meta-analysis to date (Peterson \& Hyde, 2010) found men only slightly more satisfied than women. Our survey revealed the opposite. Given the small size of the overall gender difference, this may simply reflect normal variation in sample means across studies. This gender 
difference, however, was consistent across many items, including the eleven items reported in Figure 2. There was not one item where men reported aspects of their sex life were better "now" versus "then," whereas women named four such items: lower inhibition, more single orgasms, more multiple orgasms, and feeling emotionally closer during sex now than at the beginning of the relationship. Our data may also suggest that more women have become empowered to have sex when they want it, rather than out of a sense of duty.

Taking the time to set the mood, sexual variety, and communication were important predictors of sexual satisfaction for both men and women. The current findings suggest that the profiles of sexually satisfied men and women are fairly similar, but that certain factors were of particular importance to each gender. Frequency of receiving oral sex was important for men; frequency of oral sex appeared to be less important for women, but that is due in part to the fact that orgasm consistency was also included as a predictor for women, and oral sex frequency and orgasm frequency can be highly overlapping for women. Consistency of orgasm is more much variable across women than across men (Garcia, Lloyd, Wallen, \& Fisher, 2014), allowing it to be a compelling predictor of sexual satisfaction.

\section{Limitations and Strengths}

Self-selection into surveys has been a standard problem in studies conducted with college and community samples, and now notably in many Internet surveys. The generalizability of the current findings is limited by the fact that participants were visitors to a news website who selfselected into this sample. However, the study was promoted as being on "sex and love" in an attempt to draw in a diverse range of men and women across socio-demographics and not merely those with a particular interest in sexual satisfaction. Internet samples have the advantage of being more diverse with respect to gender, sexual orientation, age, socioeconomic status, and geographic 
WHAT KEEPS PASSION ALIVE? 26

region, than convenience samples of students (Gosling \& Mason, 2015; Gosling, Vazire, Srivastava, \& John 2004). However, in our survey, as is true in many Internet surveys, respondents had more formal education than the U.S. population; in the 2014 census, $32 \%$ of Americans had college degrees or higher, in contrast to $56 \%$ of our respondents. Surveys can be completed with ease from the privacy of respondents' homes or workplaces, reaching individuals who would not otherwise have the opportunity to participate in research (for a detailed discussion of the advantages and disadvantages of Internet research, see Reips \& Birnbaum, 2011).

Our large sample size enabled us to conduct regression analyses with a large number of predictor variables, and also provided sufficient power to examine profiles of sexually satisfied men and women after segmenting them into high/low sexual satisfaction categories. However, the current study is correlational in nature, and while theory and previous literature indicate a likely causal direction, the data presented here do not provide support for causal claims. Sexual satisfaction and passion are not intrinsically stable properties of a relationship, and despite reasons to believe they generally decline, these properties may fluctuate in response to other situational factors not assessed in the current study.

Another limitation was that the study relied on a single-item measure of current sexual satisfaction, although many studies have similarly relied on global measures (notably, Laumann et al., 1994). Indeed, measurement of sexual satisfaction has been complex in the academic literature, with several slightly different validated scales available that capture various multidimensional aspects of sexual satisfaction (Mark, Herbenick, Fortenberry, Sanders, \& Reece, 2014). For assessing unidimensional aspects of sexual satisfaction, however, a single-item measure tends to perform well in psychometric comparisons and also has the practical benefit of being succinct (Mark et al., 2014). The fact that the single-item measure used correlated highly with a validated 
WHAT KEEPS PASSION ALIVE? 27

measure in a separate sample $(r=.91)$ increases confidence in the present results. Further, we assessed behaviors not routinely measured in the composite measures of past research, such as a diverse array of acts of sexual variety, mood setting techniques, expressions of intimacy and love during sex, and efficacy of using sex help books and magazines. Existing composite measures do not include any assessment of sexual satisfaction now relative to early in the relationship, although we recognize that respondents' recall can be faulty or inflated based on stereotypes that early months of romantic relationships are typically passionate. We included several items to examine differences between how people thought about their current sex life compared to those earliest months together, allowing for the possible perception that their sex life now is just as passionate, or even more so.

\section{Conclusion}

The current study extends the extant literature on sexual satisfaction. These data help establish the relative importance of predictors not only of sexual satisfaction but also lasting passion. An important contribution of the current study is that it enhances understanding of the factors that contribute to high (and sustained) sexual satisfaction and even passion in individuals who have been in a romantic relationship for three years or longer.

We end by trying to bridge some of the gap between sex research and relationship advice. Our results indicate some ways that may improve a sagging sex life: Take time to use more foreplay before sex even starts (e.g., a sexy text during the day) and to make time for intimacy by setting up "date nights," romantic getaways, and for setting the mood. Taking time with foreplay, including gentle and deep kissing, can heighten arousal and passion. Mixing it up is an important part of variety for both men and women: wearing lingerie, giving a massage, and talking about fantasies can spice up a sex life. Expressing love and cuddling after sex can boost overall feelings of sexual 


\section{WHAT KEEPS PASSION ALIVE? 28}

satisfaction. When couples run out of ideas, reading sex advice books and magazines, and actually trying out the ideas even if just for the purposes of experimenting with something new together, could help enhance overall sexual satisfaction. In sum, over time individuals and couples can, and many do, keep passion alive. 
WHAT KEEPS PASSION ALIVE? 29

\section{References}

Agnew, J. (2000). Anal manipulation as a source of sexual pleasure. Venereology, 13, 169-176. Byers, E. S. (2005). Relationship satisfaction and sexual satisfaction: A longitudinal study of individuals in long-term relationships. Journal of Sex Research, 42, 113-118. doi: $10.1080 / 00224490509552264$

Call, V., Sprecher, S., \& Schwartz, P. (1995). The incidence and frequency of marital sex in a national sample. Journal of Marriage and the Family, 57, 639-652. doi: 10.2307/353919

Castleman, M. (2008). Great sex: A man's guide to the secret principles of total-body sex. Emmaus, PA: Rodale Press.

Christopher, F. S., \& Sprecher, S. (2000). Sexuality in marriage, dating, and other relationships: A decade review. Journal of Marriage and the Family, 62, 999-1017. doi:10.1111/j.17413737.2000.00999.x

Cohen, J. (1988). Statistical power analysis for the behavioral sciences (2nd ed.). Hillsdale, NJ: Erlbaum.

Comfort, A. (1972). The joy of sex. New York: Simon and Schuster.

Crooks, R. L., \& Baur, K. (2014). Our sexuality (12th ed.). Boston, MA: Cengage.

Denes, A. (2012). Pillow talk: Exploring disclosures after sexual activity. Western Journal of Communication, 76, 91-108. doi:10.1080/10570314.2011.651253

de Visser, R. O., Smith, A. M. A., Rissel, C. E., Richters, J., \& Grulich, A. E. (2003). Sex in Australia: Heterosexual experience and recent heterosexual encounters among a representative sample of adults. Australian and New Zealand Journal of Public Health, 27, 146-154. doi:10.1111/j.1467-842X.2003.tb00802.x

Elsesser, K. M., \& Lever, J. (2011). Does gender bias against female leaders persist? Quantitative 
WHAT KEEPS PASSION ALIVE? 30

and qualitative data from a large-scale survey. Human Relations, 64, 1555-1578. doi: $10.1177 / 0018726711424323$

Fahs, B., \& Swank, E. (2013). Adventures with the 'plastic man': Sex toys, compulsory heterosexuality, and the politics of women's sexual pleasure. Sexuality \& Culture, 17, 666685. doi: 10.1007/s12119-013-9167-4

Fales, M. R., Frederick, D. A., Garcia, J. R., Gildersleeve, K. A., Haselton, M. G., \& Fisher, H. E. (2016). Mating markets and bargaining hands: Mate preferences for attractiveness and resources in two national U.S. studies. Personality and Individual Differences, 88, 78-87. doi:10.1016/j.paid.2015.08.041

Frederick, D. A., \& Fales, M. R. (in press). Upset over sexual versus emotional infidelity among gay, lesbian, bisexual, and heterosexual adults. Archives of Sexual Behavior. doi: 10.1007/s 10508-014-0409-9

Frederick, D. A., \& Jenkins, B. N. (2015). Height and body mass on the mating market: Associations with number of sex partners and extra-pair sex among heterosexual men and women aged 18-65. Evolutionary Psychology, 13, 1-26. doi: 10.1177/1474704915604563

Frederick, D. A., Lever, J., \& Peplau, L. A. (2007). Interest in cosmetic surgery and body image: Views of men and women across the lifespan. Plastic and Reconstructive Surgery, 120, 1407-1415. doi: 10.1097/01.prs.0000279375.26157.64

Frederick, D. A., Peplau, L. A., \& Lever, J. (2008). The Barbie mystique: Satisfaction with breast size and shape across the lifespan. International Journal of Sexual Health, 20, 200-211. doi: 10.1080/19317610802240170

Frederick, D. A., Peplau, L. A., \& Lever, J. (2006). The swimsuit issue: Correlates of body image in a sample of 52,677 heterosexual adults. Body Image, 4, 413-419. doi: 
WHAT KEEPS PASSION ALIVE? 31

\subsection{6/j.bodyim.2006.08.002}

Frederick, D. A., Sandhu, G., Morse, P. J., \& Swami, V. (in press). Correlates of appearance and weight satisfaction in a U.S. national sample: Personality, attachment style, television viewing, self-esteem, and life satisfaction. Body Image.

Galperin, A., Haselton, M. G., Frederick, D. A., Poore, J., von Hippel, W., Buss, D. M., \& Gonzaga, G. C. (2013). Sexual regret: Evidence for evolved sex differences. Archives of Sexual Behavior, 42, 1145-1161. doi: 10.1007/s10508-012-0019-3

Garcia, J. R., Lloyd, E. A., Wallen, K., \& Fisher, H. E. (2014). Variation in orgasm occurrence by sexual orientation in a sample of US singles. The Journal of Sexual Medicine, 11, 26452652. doi: $10.1111 /$ jsm. 12669

Gillespie, B. J., Frederick, D. A., Harari, L., \& Grov, C. (2015). Homophily, close friendship, and life satisfaction among gay, lesbian, heterosexual, and bisexual men and women. PLoS One, 10, e0128900. doi: 10.1371/journal.pone.0128900

Gillespie, B. J., Lever, J., Frederick, D. A., \& Royce, T. (2015). Close adult friendships, gender, and the life cycle. Journal of Personal and Social Relationships, 32, 709-736. doi: $10.1177 / 0265407514546977$

Gosling, S. D., \& Mason, W. (2015). Internet research in psychology. Annual Review of Psychology, 66, 877-902. doi: 10.1146/annurev-psych-010814-015321

Gosling, S. D., Vazire, S., Srivastava, S., \& John, O. P. (2004). Should we trust web-based studies? A comparative analysis of six preconceptions about internet questionnaires. American Psychologist, 59, 93-104. doi: 10.1037/0003-066X.59.2.93

Gray, P. B., Garcia, J. R., Crosier, B. S., \& Fisher, H. E. (2015). Dating and sexual behavior among single parents of young children in the United States. Journal of Sex Research, 
WHAT KEEPS PASSION ALIVE? 32

52, 121-128. doi: 10.1080/00224499.2014.941454

Grov, C., Gillespie, B. J., Royce, T., \& Lever, J. (2010). Perceived consequences of casual online sexual activities on heterosexual relationships: A U.S. online survey. Archives of Sexual Behavior, 40, 429-439. doi :10.1007/s10508-010-9598-z

Haavio-Mannila, E., \& Kontula, O. (1997). Correlates of increased sexual satisfaction. Archives of Sexual Behavior, 26, 399-419. doi: 10.1023/A:1024591318836

Hatfield, E., \& Rapson, R. L. (1993). Love, sex, and intimacy: Their psychology, biology, and history. New York: Harper Collins.

Hatfield, E., Sprecher, S., Pillemer, J. T., Greenberger, D., \& Wexler, P. (1988). Gender differences in what is desired in the sexual relationship. Journal of Psychology and Human Sexuality, 1, 39-52. doi: 10.1300/J056v01n02_04

Hatfield, E., Pillemer, J. T., O’Brien, M. U., \& Le, Y. L. (2008). The endurance of love: Passionate and companionate love in newlywed and long-term marriages. Interpersona, 2, 35-64. doi: 10.5964/ijpr.v2i1.17

Heiman, J. R., Long, J. S., Smith, S. N., Fisher, W. A., Sand, M. S., \& Rosen, R. C. (2011). Sexual satisfaction and relationship happiness in midlife and older couples in five countries. Archives of Sexual Behavior, 40, 741-753. doi: 10.1007/s10508-010-9703-3

Herbenick, D., Reece, M., Sanders, S. A., Dodge, B., Ghassemi, A. \& Fortenberry. J. D. (2010a). Women's vibrator use in sexual partnerships: Results from a nationally representative survey in the United States. Journal of Sex \& Marital Therapy, 36, 49-65. doi:

$10.1080 / 00926230903375677$ 
WHAT KEEPS PASSION ALIVE? 33

Herbenick, D., Reece, M., Schick, V., Sanders, S. A., Dodge, B., \& Fortenberry, J. D. (2010b).

Sexual behavior in the United States: Results from a national probability sample of men and women ages 14-94. Journal of Sexual Medicine, 7, 255-265. doi:

10.1111/j.1743-6109.2010.02012.x

Herbenick, D., Reece, M., Schick, V., Sanders, S. A., Dodge, B., \& Fortenberry, J. D. (2010c). An event-level analysis of the sexual characteristics and composition among adults ages 18 to 59: Results from a national probability sample in the United States. Journal of Sexual Medicine, 7, 346-61. doi: 10.1111/j.1743-6109.2010.02020.x

Hughes, S. M., \& Kruger, D. J. (2011). Sex differences in post-coital behaviors in long- and short-term mating: An evolutionary perspective. Journal of Sex Research, 48, 496-505. doi: $10.1080 / 00224499.2010 .501915$

Jankowiak, W. R., Volsche, S. L., \& Garcia, J. R. (2015). Is the romantic-sexual kiss a near human universal? American Anthropologist, 117, 535-539. doi: 10.1111/aman.12286

Kaestle, C. E., \& Halpern, C. T. (2007). What's love got to do with it? Sexual behaviors of opposite-sex couples through emerging adulthood. Perspectives on Sexual and Reproductive Health, 39, 134-140. doi: 10.1363/3913407

Kinsey, A. C., Pomeroy W. B., \& Martin, D. E. (1948). Sexual behavior in the human male. Philadelphia, PA: W.B. Saunders.

Kinsey, A. C., Pomeroy W. B., Martin, D. E., \& Gebhard, P. H. (1953). Sexual behavior in the human female. Philadelphia, PA: W.B. Saunders.

Laumann, E. O., Gagnon, J. H., Michael, R. T., \& Michaels, S. (1994). The social organization of sexuality: Sexual practices in the United States. Chicago: University of Chicago Press.

Lawrance, K., \& Byers, E. S. (1995). Sexual satisfaction in long-term heterosexual relationship: 
WHAT KEEPS PASSION ALIVE? 34

The interpersonal exchange model of sexual satisfaction. Personal Relationships, 2, 267285. doi: 10.1111/j.1475-6811.1995.tb00092.x

Lever, J., Frederick, D. A., \& Hertz, R. (2015). Paying for dates: Following versus challenging gender norms. SAGE Open, 5. doi: 10.1177/2158244015613107

Lever, J., Frederick, D. A., Laird, K., \& Sadeghi-Azar, L. (2007). Tall women's satisfaction with their height: General population data challenge assumptions behind medical interventions to stunt girls' growth. Journal of Adolescent Health, 40, 192-194. doi: 10.1016/j.jadohealth.2006.09.004

Lever, J., Frederick, D. A., \& Peplau, L. A. (2006). Does size matter? Men's and women’s views on penis size across the lifespan. Psychology of Men \& Masculinity, 7, 129-143. doi: $10.1037 / 1524-9220.7 .3 .129$

MacNeil, S., \& Byers, E. S. (2005). Dyadic assessment of sexual self-disclosure and sexual satisfaction in heterosexual dating couples. Journal of Social and Personal Relationships, 22, 169-181. doi: 10.1177/0265407505050942

Mark, K. P., Garcia, J. R., \& Fisher, H. E. (2015). Perceived emotional and sexual satisfaction across sexual relationship contexts: Gender and sexual orientation differences and similarities. The Canadian Journal of Human Sexuality, 24, 120-130. doi: $10.3138 /$ cjhs. $242-\mathrm{a} 8$

Mark, K. P., Herbenick, D., Fortenberry, J. D., Sanders, S., \& Reece, M. (2014). A psychometric comparison of three scales and a single-item measure to assess sexual satisfaction. Journal of Sex Research, 51, 159-169. doi: 10.1080/00224499.2013.816261

McBride, K. R., \& Fortenberry, J. D. (2010). Heterosexual anal sexuality and anal sex behaviors: A review. Journal of Sex Research, 47, 123-136. doi: 10.1080/00224490903402538 
WHAT KEEPS PASSION ALIVE? 35

Montesi, J. L., Fauber, R. L., Gordon, E. A., \& Heimberg, R. G. (2010). The specific importance of communication about sex to couple's sexual and overall relationship satisfaction. Journal of Social and Personal Relationships, 28, 591-609. doi: 10.1177/0265407510386833

Morin, J. (2010). Anal pleasure and health: A guide for men, women and couples. San Francisco, CA: Down There Press.

Muise, A., Giang, E., \& Impett, E. A. (2014). Post sex affectionate exchanges promote sexual and relationship satisfaction. Archives of Sexual Behavior, 43, 1391-1402. doi: $10.1007 / \mathrm{s} 10508-014-0305-3$

National Institutes of Health (2010). Human subjects research - exemptions. Retrieved 12/28/2015 from: http://grants.nih.gov/grants/policy/hs/faqs_aps_exempt.htm\#304

NBC News. (2012). Media kit. Retrieved from http://www.nbcnews.com/id/31066137

O’Leary, K. D., Acavedo, B. P., Aron, A., Huddy, L., \& Mashek, D. (2012). Is long-term love more than a rare phenomenon? If so, what are its correlates? Social Psychological and Personality Science, 3, 241-249. doi: 10.1177/1948550611417015

Pasta, D. J. (2009, May). Learning when to be discrete: Continuous vs. categorical predictors. Statistical Analysis System (SAS) Global Forum, Washington, D.C. support.sas.com/resources/papers/proceedings09/248-2009.pdf

Peplau, L. A., Frederick, D. A., Yee, C., Maisel, N., Lever, J., \& Ghavami, N. (2009). Body image satisfaction in heterosexual, gay, and lesbian adults. Archives of Sexual Behavior, 38, 713-725. doi: 10.1007/s10508-008-9378-1

Petersen, J. L., \& Hyde, J. S. (2010). A meta-analytic review of research on gender differences in sexuality, 1993-2007. Psychological Bulletin, 136, 21-38. doi: 10.1037/a0017504

Poulsen, F. O., Busby, D. M., \& Galovan, A. M. (2013). Pornography use: Who uses it and how it 


\section{WHAT KEEPS PASSION ALIVE? 36}

is associated with couple outcomes. Journal of Sex Research, 50, 72-83. doi:

$10.1080 / 00224499.2011 .648027$

Rehman, U., Fallis, E., \& Byers, E. S. (2013). Sexual satisfaction in heterosexual women. In D. Castañeda (Ed.), An essential handbook of women's sexuality (Vol. 1, pp. 25-45). Westport, $\mathrm{CN}$ : Praeger.

Reips, U., \& Birnbaum, M. H. (2011). Behavioral research and data collection via the Internet. In K. L. Vu and R. W. Proctor (Eds.), The handbook of human factors in web design (2nd ed., pp. 563-585). Mahwah, NJ: Erlbaum. doi: 10.1201/b10855-37

Sanchez-Fuentes, M., Santos-Iglesias, P., \& Sierra, J. C. (2014). A systematic review of sexual satisfaction. International Journal of Clinical and Health Psychology, 14, 67-75. doi:10.1016/S1697-2600(14)70038-9

Singh, D., Meyer, W., Zambarano, R. J., \& Hurlbert, D. F. (1998). Frequency and timing of coital orgasm in women desirous of becoming pregnant. Archives of Sexual Behavior, 27, 15-29. doi: 10.1023/A:1018653724159

Smith, T. W., \& Son, J. (2013). Trends in public attitudes about sexual morality. NORC at the University of Chicago. Retrieved from: http://www.norc.org/PDFs/sexmoralfinal_0621_FINAL.PDF

Sprecher, S. (2002). Sexual satisfaction in premarital relationships: Associations with satisfaction, love, commitment, and stability. Journal of Sex Research, 39, 190-196. doi: $10.1080 / 00224490209552141$

Sprecher, S., \& Cate, R. M. (2004). Sexual satisfaction and sexual expression as predictors of relationship satisfaction and stability. In J. H. Harvey, A. Wenzel, \& S. Sprecher (Eds.), 
1

2

3

4

5

6

7

8

9

10

11

12

13

14

15

16

17

18

19

20

21

22

23

24

25

26

27

28

29

30

31

32

33

34

35

36

37

38

39

40

41

42

43

44

45

46

47

48

49

50

51

52

53

54

55

56

57

58

59

60

WHAT KEEPS PASSION ALIVE? 37

The handbook of sexuality in close relationships (pp. 235-256). Mahwah, NJ: Lawrence Erlbaum.

Sternberg, R. J. (1986). A triangular theory of love. Psychological Review, 93, 119-135. doi: 10.1037/0033-295x.93.2.119

van Anders, S. M., Edelstein, R. S., Wade, R. M., \& Samples-Steele, C. R. (2013). Descriptive experiences and sexual vs. nurturant aspects of cuddling between adult romantic partners. Archives of Sexual Behavior, 42, 553-560. doi: 10.1007/s10508-012-0014-8 


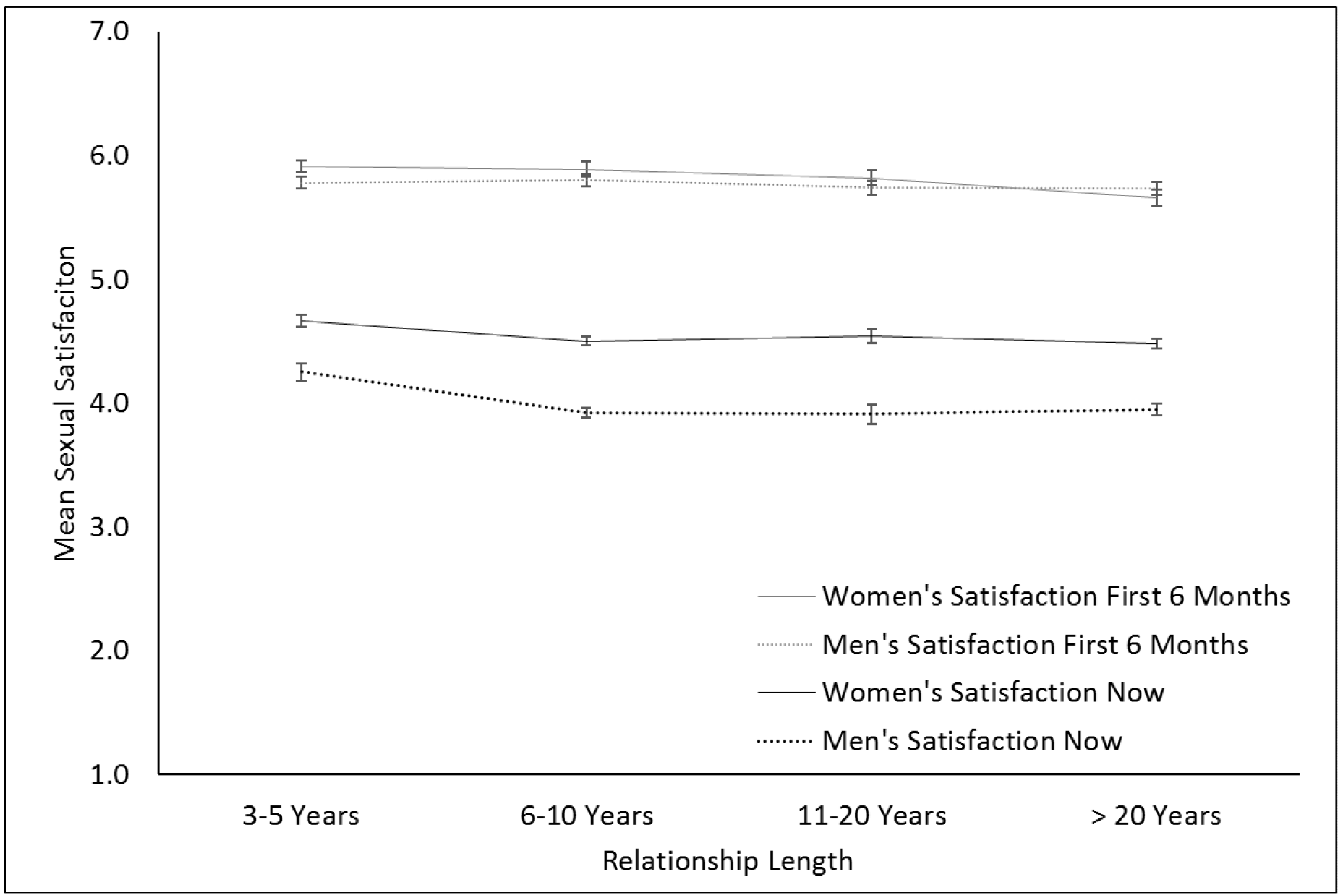

Figure 1. Men and women reports of their sexual satisfaction now versus their recollection of their sexual satisfaction during the first six months of their relationship.

Note. Error bars represent $95 \%$ confidence intervals. 


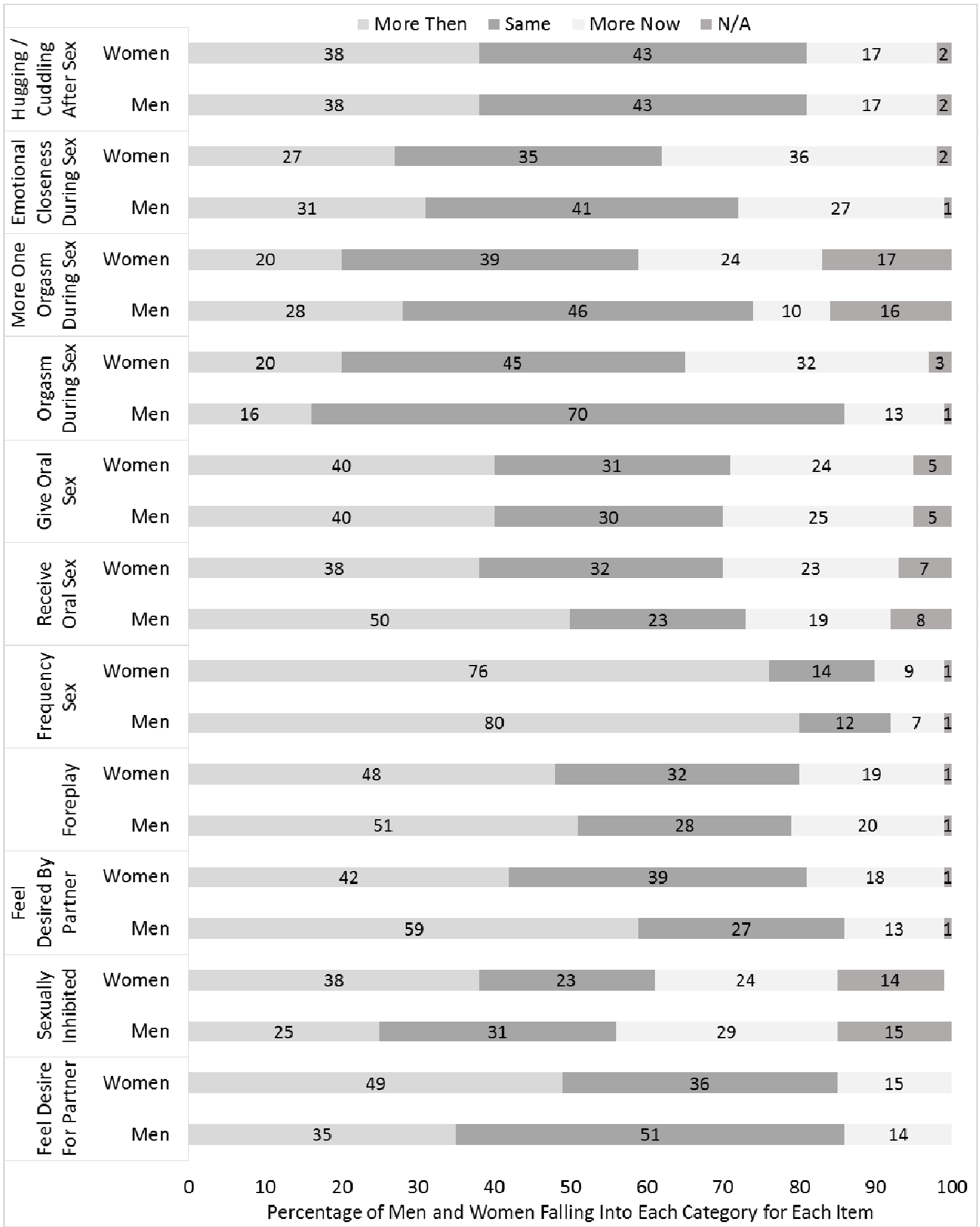

Figure 2. Men's and women's reports of whether the behavior/feeling was more common when they first started having sex than now (then), same as now (same), moreso now (more now), or not applicable (N/A). 


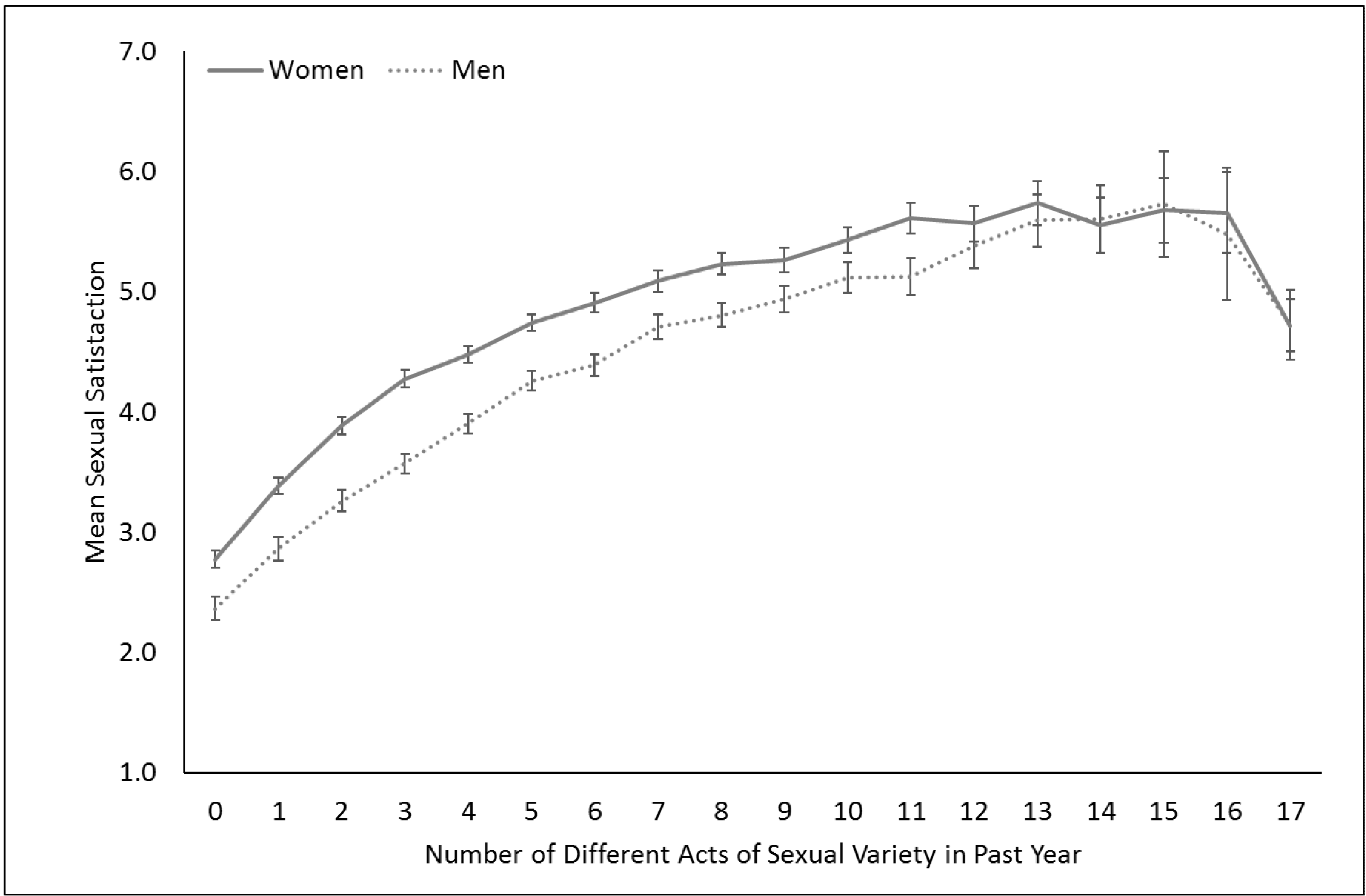

Figure 3. Degree of sexual satisfaction among men and women who engaged in different numbers of acts of sexual variety in the past year.

Note. Error bars represent $95 \%$ confidence intervals. 


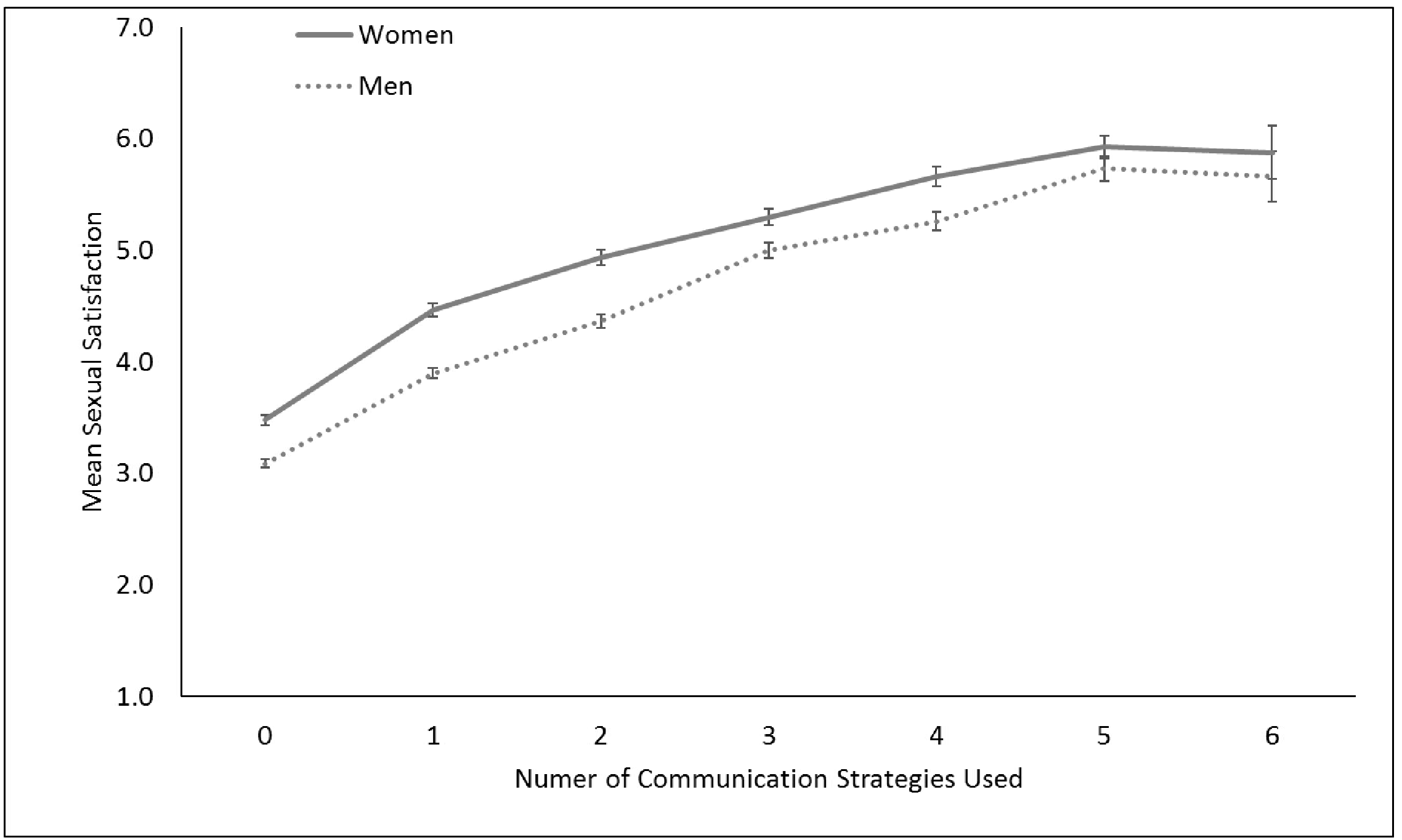

Figure 4. Degree of sexual satisfaction among men and women who used different numbers of communication strategies. Note. Error bars represent $95 \%$ confidence intervals. 
Table 1. Key demographics for analyzed sample $(N=38,747)$.

\begin{tabular}{ccc} 
Overall & Men & Women \\
\hline$\%$ & $\%$ & $\%$ \\
$(\mathrm{~N})$ & $(\mathrm{N})$ & $(\mathrm{N})$
\end{tabular}

\begin{tabular}{ccc} 
Overall & Men & Women \\
\hline$\%$ & $\%$ & $\%$
\end{tabular}

$(\mathrm{N})$

$(\mathrm{N})$

$(\mathrm{N})$

Ethnicity

Gender

59

41

White

$\begin{array}{lll}88 & 86 & 88\end{array}$ $(34,100) \quad(13,537) \quad(20,563)$

Black

2

2

2 (882) (389) (493)

Hispanic

$\begin{array}{ccc}3 & 4 & 3 \\ (1,295) & (659) & (636)\end{array}$

Asian

2

2

2

(674) (280) (394)

Native

$1 \quad 1$

1

American

(186)

(98)

(88)

Other

(221)

(107)

(114)

Biracial

$\begin{array}{cc}1 & 1 \\ (411) & (225)\end{array}$

1

(186)

Prefer Not to

$2 \quad 3$

2

Say

(978) (430)

(548)

Education

Some High

School or Less

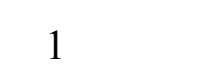

High School

Graduate

(270) (156)

1

35

36

37

38

39

40

41

42

43

44

45

46

47

48

49

50

51

52

53

54

55

Some College

$\begin{array}{lll}9 & 13 & 7\end{array}$

$(3,587) \quad(2,007) \quad(1,580)$

Associates

34

29

College Degree

$(13,042) \quad(6,346) \quad(6,696)$

Graduate

36

33

38

$(14,004) \quad(5,112) \quad(8,892)$

Degree

$\begin{array}{lll}20 & 13 & 25\end{array}$

Yes

Relationship

Length

3-5 Years

$(23,022)$

$(15,725)$

Relationship

Status

Cohabitating

$\begin{array}{ccc}10 & 16 & 6 \\ (3,986) & (2,558) & (1,428)\end{array}$

Married

83

77

87

Remarried

$(32,168)$

$(12,119) \quad(20,049)$

7
$(2,593)$

7

7

$(2,593)$

$(1,048)$

$(1,545)$

\section{6-10 Years}

$(7,314)$

26

14

$6-10$ Years

25

$(4,174)$

$(3,140)$

$(9,805)$

30

22

11-20 Years

33

$(4,671)$

$(5,134)$

$(12,557)$

29

35

$>20$ Years

23

$(4,516)$

$(8,041)$

Children

$(9,071)$

15

29

Under 21

No 
Table 2. Predictors of Sexual Satisfaction and Passion among Men and Women.

\begin{tabular}{|c|c|c|c|c|c|c|c|c|}
\hline & \multicolumn{4}{|c|}{ Sexual Satisfaction } & \multicolumn{4}{|c|}{ Passion } \\
\hline & \multicolumn{2}{|c|}{ Model 1} & \multicolumn{2}{|c|}{ Model 2} & \multicolumn{2}{|c|}{ Model 1} & \multicolumn{2}{|c|}{ Model 2} \\
\hline & Men & Women & Men & Women & Men & Women & Men & Women \\
\hline & $\beta$ & $\beta$ & $\beta$ & $\beta$ & $\beta$ & $\beta$ & $\beta$ & $\beta$ \\
\hline Age & .08 & .04 & .07 & .02 & .07 & .07 & .07 & .05 \\
\hline Relationship Length & .02 & .04 & .03 & .04 & .02 & .01 & .03 & .01 \\
\hline Education & -.01 & .01 & -.01 & .00 & -.03 & -.04 & -.03 & -.05 \\
\hline Kids Under 21 & .01 & .02 & .01 & .01 & .01 & .02 & .01 & .02 \\
\hline Your Orgasm & .05 & .19 & .11 & .27 & .02 & .15 & .07 & .22 \\
\hline Partner Orgasm & .08 & .03 & .11 & .08 & .09 & -.01 & .12 & .03 \\
\hline Receive Oral & .07 & .03 & .13 & .03 & .05 & .01 & .10 & .01 \\
\hline Give Oral & .01 & .02 & -.01 & .04 & .03 & .06 & .01 & .08 \\
\hline Sexual Variety (0-17) & .07 & .03 & .18 & .10 & .05 & .04 & .14 & .10 \\
\hline Mood Setting (0-5) & .10 & .10 & .20 & .20 & .13 & .15 & .20 & .22 \\
\hline Communication $(0-5)$ & .07 & .07 & .18 & .18 & .07 & .06 & .17 & .16 \\
\hline Relationship Sat. & .39 & .38 & - & - & .27 & .25 & - & - \\
\hline Sex Frequency & .30 & .27 & - & - & .29 & .28 & - & - \\
\hline$d f$ & 13 & 13 & 11 & 11 & 13 & 13 & 11 & 11 \\
\hline$N$ & 20,581 & 14,386 & 20,612 & 14,389 & 20,541 & 14,360 & 20,564 & 14,368 \\
\hline$F$ & 1,848 & 1,161 & 805 & 599 & 1,071 & 731 & 632 & 481 \\
\hline $\operatorname{Adj} R^{2}$ & .54 & .51 & .30 & .31 & .40 & .40 & .25 & .27 \\
\hline
\end{tabular}

Note. All $\beta$ values greater than $|.03|$ were significant at the $p<.001$ level, and all of the regression models were as well. Positive $\beta$ s indicate that participants who scored higher on the predictor variables were more sexually satisfied (e.g., in Model 1, women who reported more consistent orgasms reported greater sexual satisfaction, $\beta=.19$ ). Model 1 includes relationship satisfaction and sex frequency as predictors, whereas Model 2 does not. 
Table 3. Orgasm Consistency and Frequency of Oral Sex and Sex Among Sexually Satisfied, Neutral, and Dissatisfied Men and Women.

\section{Participant Orgasms in Past Month}

Usually/Always

About half of the time

Never/Rarely

\section{Partner Orgasms in Past Month}

Usually/Always

About half of the time

Never/Rarely

\section{Participant Received Oral Sex Past Month}

Usually/Always

About half of the time

Never/Rarely

\section{Participant Gave Oral Sex Past Month}

Usually/Always

About half of the time

Never/Rarely

Sat. Neut. Dis. $\chi^{2}$

$\begin{array}{cccc}98 & 94 & 91 & 612 \\ 1 & 4 & 4 & \\ 1 & 2 & 5 & \end{array}$

Sat. Neut. Dis. $\chi^{2}$

$\begin{array}{cccc}78 & 54 & 41 & 2,315 \\ 15 & 22 & 19 & \\ 7 & 24 & 42 & \end{array}$

431

$\begin{array}{ccc}98 & 95 & 80 \\ 2 & 3 & 4 \\ 1 & 2 & 6\end{array}$

$\begin{array}{ccc}79 & 66 & 61 \\ 14 & 18 & 14 \\ 7 & 16 & 25\end{array}$

$\begin{array}{llll}31 & 20 & 15 & 1,889 \\ 26 & 20 & 14 & \\ 43 & 60 & 71 & \end{array}$

$\begin{array}{lll}30 & 23 & 18 \\ 27 & 21 & 17 \\ 43 & 56 & 64\end{array}$

711

$\begin{array}{lll}56 & 29 & 37 \\ 15 & 22 & 25 \\ 29 & 49 & 38\end{array}$

1,063

$\begin{array}{lll}30 & 24 & 24 \\ 31 & 21 & 19 \\ 39 & 55 & 57\end{array}$

\begin{tabular}{ccc}
\multicolumn{3}{c}{ Gender Diff. } \\
\hline $\mathrm{M}$ & $\mathrm{W}$ & $\chi^{2}$ \\
\hline & & \\
95 & 66 & 7,633 \\
3 & 17 & \\
2 & 18 &
\end{tabular}

$\begin{array}{lll}727 & 37 & 28 \\ & 25 & 27 \\ & 38 & 45\end{array}$

$\begin{array}{cc}71 & 96 \\ 14 & 2 \\ 15 & 2\end{array}$

6,833

\section{Sex Frequency}

$3+$ times per week

1-2 times per week

$\begin{array}{cccc}30 & 6 & 2 & 8,276 \\ 49 & 37 & 15 & \\ 21 & 56 & 76 & \\ 0 & 1 & 7 & \end{array}$

$\begin{array}{ccc}36 & 8 & 6 \\ 45 & 37 & 17 \\ 19 & 54 & 70 \\ 0 & 1 & 7\end{array}$

\begin{tabular}{ccc}
4,963 & 15 & 23 \\
& 33 & 36 \\
49 & 39 \\
3 & 2 \\
\hline
\end{tabular}

552

Note. Chi-Square analyses tested if the proportion of people responding in each category differ depending on sexual satisfaction. All analyses were significant at the $p<.001$ level. Percentages indicate the percent of people who fell into each category at each level of sexual satisfaction. For example, among sexually satisfied men, $98 \%$ reported always/usually having orgasms during sex, $1 \%$ about half the time, and $1 \%$ never/rarely. 
Table 4. Acts of Sexual Variety and Sexual Communication Among Sexually Satisfied, Neutral, and Dissatisfied Men and Women.

\section{Acts of Sexual Variety Past Year (\% Yes)}

At least one of us got a mini-massage or backrub

One of us wore sexy lingerie/underwear

Took a shower or bath together

Made a "date night" to be sure we had sex

Tried a new sexual position

Went on a romantic getaway

Used a vibrator or sex toy together

Tried anal stimulation

Viewed pornography together

Talked about or acted out our fantasies

Had anal intercourse

Had sexual contact in a public place

Integrated food into sex (e.g., chocolate/whipped cream)

Tried light S\&M (e.g., restraints, spanking)

One of us took Viagra or a similar drug

Videotaped our sex or posed for pictures in the nude

Invited another person into bed with us

\section{Communication Past Month (\% Yes)}

I asked for something I wanted in bed

One of us praised other about something they did in bed

My partner asked for something they wanted in bed

One of us asked for feedback on how something felt

One us gently criticized how other did something in bed 7

Men

Sat. Neut. Dis. $\chi^{2}$

$72 \quad 58$

$67 \quad 48$

$64 \quad 50$

$63 \quad 53$

$59 \quad 36$

$53 \quad 39$

$48 \quad 39$

$42 \quad 28$

$40 \quad 29$

$\begin{array}{ll}40 & 22 \\ 25 & 15\end{array}$

$23 \quad 10$

$\begin{array}{ll}23 & 10 \\ 22 & 13\end{array}$

189

$17 \quad 14$

159

63

$\begin{array}{llll}51 & 33 & 28 & 1,126 \\ 50 & 22 & 12 & 3,434 \\ 37 & 15 & 8 & 2,589 \\ 34 & 18 & 13 & 1,237 \\ 33 & 17 & 11 & 1,513 \\ 7 & 7 & 7 & \text { n.s. }\end{array}$

Note. Chi-Square analyses tested if the percentage of

-

\footnotetext{
ercentage of people responding yes to each item differed according to level of sexual satisfaction. Chi-square values are listed for all statistically significant effects. Percentages indicate the percent of people who said yes to each item. For example, among sexually satisfied men, $72 \%$ reported getting a mini-massage or backrub (28\% did not). The last column "overall" compares men's and women's reports.
} 
Table 5. Reports of Events During Last Sexual Encounter (DLS) Among Sexually Satisfied, Neutral, and Dissatisfied Men and Women.

\section{What Happened DLS: Mood Setting (\% Yes)}

At least one of us said "I love you"

We engaged in sexy talk

Laughed about something funny happened during sex

Lit a candle or dimmed the lights

Played music in the background

\begin{tabular}{c}
\multicolumn{2}{c}{ Men } \\
\hline Sat. Neut. Dis. $\chi^{2}$
\end{tabular}

\begin{tabular}{cccc}
\multicolumn{4}{c}{ Women } \\
\hline Sat. & Neut. & Dis. & $\chi^{2}$ \\
\hline 74 & 54 & 44 & 1,148 \\
46 & 19 & 13 & 1,663 \\
36 & 20 & 14 & 782 \\
20 & 11 & 9 & 327 \\
11 & 6 & 6 & 134
\end{tabular}

\begin{tabular}{ll}
\multicolumn{2}{c}{ Overall } \\
$\mathrm{M} \mathrm{W} \chi^{2}$ \\
\hline
\end{tabular}

\section{What Happened DLS: Acts (\% Yes)}

Vaginal intercourse

Manual stimulation of genitals

Gentle kissing

Deep kissing

Changed positions during sexual intercourse

Gave oral sex

Received oral sex

Anal intercourse

$\begin{array}{cccc}75 & 60 & 49 & 1,327 \\ 44 & 20 & 13 & 2,436 \\ 28 & 17 & 11 & 877 \\ 23 & 14 & 11 & 502 \\ 14 & 8 & 6 & 355\end{array}$

$\begin{array}{cccc}95 & 92 & 90 & 168 \\ 89 & 81 & 73 & 768 \\ 84 & 75 & 67 & 696 \\ 69 & 55 & 46 & 1,130 \\ 65 & 47 & 37 & 1,656 \\ 50 & 40 & 35 & 464 \\ 49 & 37 & 27 & 1,067 \\ 6 & 3 & 2 & 195\end{array}$

$\begin{array}{ccccccc}96 & 93 & 91 & 122 & 92 & 94 & 36 \\ 87 & 73 & 66 & 768 & 81 & 79 & 43 \\ 81 & 64 & 54 & 1,094 & 76 & 71 & 110 \\ 70 & 49 & 39 & 1,223 & 57 & 58 & \text { n.s } \\ 69 & 52 & 42 & 912 & 50 & 58 & 246 \\ 48 & 35 & 33 & 360 & 42 & 42 & \text { n.s. } \\ 43 & 35 & 28 & 288 & 38 & 38 & \text { n.s. } \\ 5 & 3 & 2 & 55 & 4 & 4 & \text { n.s. }\end{array}$

\section{ONE Best Describes Feelings DLS (\% in each cat.)}

\section{Passionate}

Loving and tender

Playful

Happy to be getting release from tension

$\begin{array}{ccc}40 & 16 & 12 \\ 26 & 21 & 12 \\ 15 & 13 & 6 \\ 15 & 37 & 47 \\ 1 & 9 & 13 \\ 1 & 2 & 2\end{array}$

5,531

$\begin{array}{ccccccc}34 & 9 & 7 & 4,554 & 25 & 22 & 2,958 \\ 30 & 18 & 12 & & 19 & 23 & \\ 17 & 13 & 7 & & 11 & 13 & \\ 10 & 17 & 19 & & 32 & 14 & \\ 7 & 35 & 43 & & 7 & 21 & \\ 1 & 5 & 7 & & 2 & 3 & \end{array}$

\section{$1+$ Hour}

\section{Length of Sex DLS (\% in each cat.)}

30-60 minutes

15-30 minutes

$\begin{array}{ccc}12 & 4 & 4 \\ 37 & 26 & 22 \\ 42 & 47 & 44 \\ 11 & 23 & 30\end{array}$

1,640

$\begin{array}{ccc}9 & 3 & 3 \\ 36 & 22 & 16 \\ 42 & 44 & 39 \\ 13 & 31 & 42\end{array}$

$\begin{array}{ccc}1,875 & 7 & 6 \\ & 29 & 28 \\ 43 & 42 \\ & 21 & 24\end{array}$

Table 5 Note. For the top two questions, Chi-square analyses tested if the percentage of people responding yes for each item differed according to level of sexual satisfaction. Chi-square values are listed for all statistically significant effects. For the bottom two questions, percentages indicate the percent of people who fell in each category at each level of sexual satisfaction. 
Table 6. Beliefs and Attitudes About Sex Life Among Sexually Satisfied, Neutral, and Dissatisfied Men and Women.

\section{More or Same Now as In Beginning (\% Agree)}

Feel desire for your partner

Feel sexually inhibited (negative trait)

Foreplay

Frequency of sex

Frequency receiving oral sex

Frequency giving oral sex

Frequency reach orgasm during sex

More than one orgasm during sex

Hugging/cuddling after sex
Feel desired by your partner

Emotional closeness during sex

\begin{tabular}{lll}
\multicolumn{2}{c}{ Men } \\
\hline Sat. Neut. Dis. $\chi^{2}$ \\
\hline
\end{tabular}

Read Magazines and Try Out Ideas? (\% in each cat.)

Yes, and some ideas worked for us

Yes, we've tried some ideas, but didn't work for us

Yes, but we never really test out the ideas

No

\section{Attitudes About Sex Life (\% Agree)}

I feel happy with my relationship overall

It is important to me to have exciting sex life

I feel comfortable asking my partner for what I want in bed

I am satisfied with variety of sexual positions w/ partner

Our sex life is predictable

Sex life is as passionate now as in beginning

Sex life is as spontaneous now as in beginning

I found partner more physically attractive in beginning

I feel like I' $m$ not good enough in bed with my partner

I feel that my partner doesn't know how to excite me

$\begin{array}{llll}76 & 58 & 56 & 1,226 \\ 65 & 80 & 83 & 2,555 \\ 65 & 35 & 18 & 4,904 \\ 69 & 45 & 30 & 3,588 \\ 36 & 11 & 6 & 3,423 \\ 68 & 44 & 34 & 3,289 \\ 74 & 58 & 46 & 2,037 \\ 94 & 85 & 72 & 2,676 \\ 81 & 71 & 62 & 1,856 \\ 89 & 71 & 46 & 5,329 \\ 80 & 62 & 44 & 3,296\end{array}$

$\begin{array}{llll}20 & 9 & 5 & 1,421 \\ 4 & 5 & 6 & \\ 19 & 28 & 33 & \\ 57 & 58 & 56 & \end{array}$

9890

$94 \quad 88$

$\begin{array}{ll}57 & 5,275 \\ 94 & 167 \\ 43 & 4,143 \\ 23 & 5,302 \\ 85 & 775 \\ 7 & 7,366 \\ 4 & 4,687 \\ 49 & 606 \\ 40 & 792 \\ 61 & 3,780\end{array}$

\begin{tabular}{cc} 
& \multicolumn{2}{r}{ Sat. } & Neut. \\
\hline 67 & 32 \\
55 & 68 \\
74 & 48 \\
67 & 39 \\
36 & 10 \\
74 & 54 \\
71 & 53 \\
93 & 75 \\
90 & 76 \\
90 & 62 \\
80 & 57
\end{tabular}

Women

$\begin{array}{lllllll}24 & 11 & 7 & 912 & 13 & 17 & 340 \\ 4 & 7 & 8 & & 5 & 6 & \\ 24 & 34 & 40 & & 26 & 30 & \\ 49 & 48 & 45 & & 57 & 48 & \end{array}$

Dis.

$\chi^{2}$

\begin{tabular}{lll}
\multicolumn{3}{c}{ Overall } \\
\hline $\mathrm{M}$ & $\mathrm{W} \quad \chi^{2}$ \\
\hline
\end{tabular}

87

$75 \quad 43$

$71 \quad 88$

$62 \quad 14$

439

$32 \quad 44$

$22 \quad 37$

$18 \quad 42$

30
72
32
30
8
44
43
58
65
46
46

7
8
40
45

2,285

1,055

2,409

2,253

1,941

1,662

1,301

3,111

2,284

3,860

2,215

$\begin{array}{lll}65 & 51 \quad 916\end{array}$

$\begin{array}{lll}75 & 62 & 749\end{array}$

$\begin{array}{lll}41 & 58 & 1,072\end{array}$

$\begin{array}{lll}49 & 52 & 73\end{array}$

$\begin{array}{lll}20 & 24 & 94\end{array}$

$60 \quad 60$

$84 \quad 80 \quad 2,837$

$\begin{array}{lll}84 & 80 & 2,837\end{array}$

$\begin{array}{lll}69 & 72 \quad 412\end{array}$

$\begin{array}{lll}62 & 67 & 117\end{array}$

$75-65$

$\begin{array}{lll}50 & 62 & 713\end{array}$

$\begin{array}{lll}71 & 80 & 1,610\end{array}$

Note. Chi-Square analyses tested if the percentage of people responding yes, responding in each category, or who agreed with the items differed according to level of sexual satisfaction. Chi-square values are listed for all statistically significant effects. 